\title{
Complementary feeding of premature infants: a challenge
}

\author{
Brunnella Alcantara Chagas de Freitas ${ }^{1}$ (1) *, Luciana Moreira Lima ${ }^{1}$, \\ Emanuelle Emília Ferreira Parreiras ${ }^{1}\left(\mathbb{D}\right.$, Tatiana Cristina Serafim ${ }^{1}$ (1), \\ Kelvin Oliveira Rocha' ${ }^{1}$, Felipe Oliveira Martins ${ }^{10}$, Flávia Galvão Cândido²
}

\section{INTRODUCTION}

Complementary feeding is of high risk for premature children due to feeding difficulties, not recommended foods, food contamination risks, and the fact that nutritional quality may not meet or exceed the needs for nutrients and energy ${ }^{1,2}$.

These factors are a cause for concern, since premature children are at greater risk of postnatal growth deviation, both in terms of acceleration and failure. There is also evidence that postnatal growth has significant long-term consequences and can be influenced by the time and type of solid foods offered ${ }^{3-5}$. For this reason, correct guidance offered to caregivers plays a fundamental role and should be offered by health professionals. However, surprisingly, there are no evidence-based guidelines for preterm infants, which leads to different and contrasting approaches on the part of caregivers and health professionals ${ }^{1,2,6}$.

Considering the absence of guidelines for premature children, this review aims to analyze the scientific evidence regarding complementary feeding practices in premature children published over the past five years.

\section{METHODOLOGY}

This integrative review was based on the recommendations of the Preferred Reporting Items for Systematic Reviews (PRISMA) at all stages of design, implementation, and reporting?.

A bibliographic survey was carried out from June to July 2019, in the following databases: Publisher Medline (Pubmed), LatinAmerican and Caribbean Center on Health Sciences Information
(Lilacs), Scientific Electronic Library Online (Scielo), and Library Cochrane. Manual searches of references were also carried out in the selected studies to identify papers that had not been found in the databases, which were handled according to the same analysis protocol. As a search engine, we used "premature infant" AND "complementary feeding". The following filters were selected: humans, free full text, last five years, English language, infant age group.

The inclusion criteria for the review were: any original article that investigated the introduction of complementary feeding in premature infants that had been published over the past five years. Complementary feeding was defined as the introduction of semi-solid, soft, or solid foods other than breast milk, formula, or animal milk. The exclusion criteria were: studies that did not assess premature infants; those in which the term "weaning" had been used to indicate transition from breast-feeding to formula or animal milk, instead of semi-solid, soft or solid foods; those evaluating infants less than six months after hospital discharge; review studies; congress publications; theses and dissertations.

Two independent reviewers, including analysis of the title, abstract, and reading of the full text, selected the studies in two phases. A third reviewer resolved any disagreements. The steps included identification of papers in the databases, exclusion of duplicate files, initial selection by title and abstract, and complete analysis of the manuscripts that met the eligibility criteria. Duplicate papers in different databases were identified using Mendeley Desktop program.

The results were extracted and systematized using a Microsoft Excel $^{\oplus}$ document. The results were organized according to the

\footnotetext{
'Universidade Federal de Viçosa, Department of Medicine and Nursing - Viçosa (MG), Brazil.

${ }^{2}$ Universidade Federal de Viçosa Postgraduate Program in Nutrition Science - Viçosa (MG), Brazil.

*Corresponding author: brunnella.freitas@ufv.br

Conflicts of interest: the authors declare there are no conflicts of interest. Funding: none.

Received on November 01, 2020. Accepted on November 29, 2020.
} 
specific purposes of knowing the following evidence about complementary feeding of premature infants: (1) Studies on the timing of food introduction and its composition; (2) Difficulties encountered and parents' perceptions; (3) Conduct of health professionals.

\section{RESULTS}

The initial screening identified 113 titles. No duplicate files were found. Of these, 86 were excluded by reading the title and abstract, totaling 27 remaining papers. Once the entire paper had been read to assess the pre-established eligibility criteria, six original papers were included in this review. The details of the selection process are shown in Figure 1. The main characteristics of the studies are shown in Table 1.

\section{Time of introduction and composition of complementary feeding}

Three studies were analyzed from this perspective.

The study by Gupta et al. ${ }^{8}$, carried out in India, is a randomized multicenter trial with children born at less than 34 gestational weeks, compared using two groups, according to the introduction of complementary feeding at four or six months of corrected gestational age (CGA), and followed up to 12 months of CGA. The type of food varied, from semisolid to solid, based on WHO recommendations. Parents were advised to continue offering breast milk, be aware of food safety during food preparation, quantity, consistency, frequency, and composition. From two weeks onwards, iron and vitamin D supplementation was recommended. Upon completing 12 months of corrected age, patients were evaluated under the following aspects: height, weight, and body mass index by age (z-score), bone mineral density, lipid profile, HOMA-IR index, blood pressure, serum ferritin, psychomotor development, hospital admission rate, and disease recurrence.

The most striking result of Gupta et al. ${ }^{8}$ when comparing both groups was regarding the hospital admission rate. In the study, those who started complementary feeding after four months of CGA had a $52 \%$ increased risk of hospital admission due to various complications, with more episodes of diarrhea and of lower airway infections up to the age of 12 months of CGA. The authors believe these are due to complementary food being potentially contaminated and to the decreased immunological benefit of breast milk. Thus, they recommend that complementary feeding of premature children born before 34 gestational weeks starts at six months of CGA, depending on the risks and benefits.

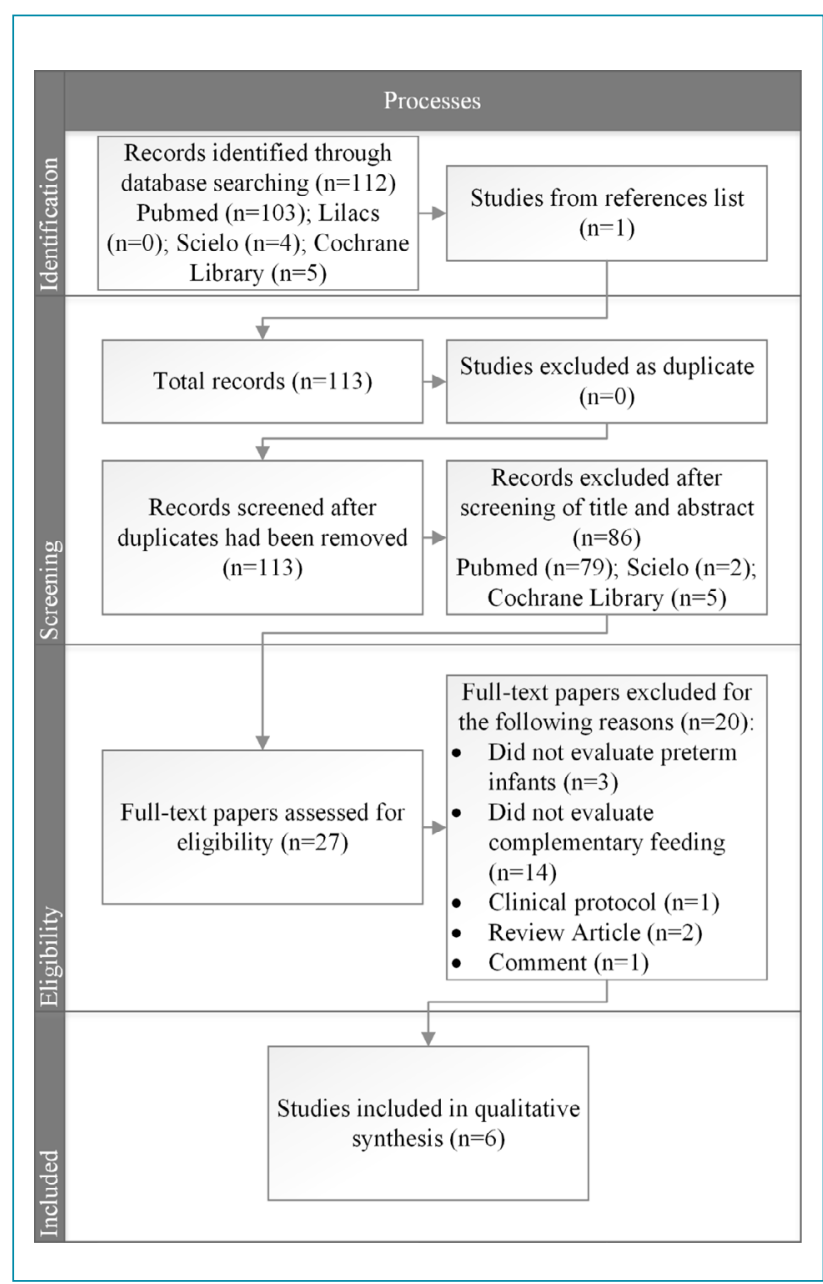

Figure 1. Flowchart of bibliographic research and study selection procedures in accordance with PRISMA recommendations ${ }^{7}$.

Brusco \& Delgado 9 , in a cross-sectional study carried out in Brazil with preterm infants between three and twelve months of age, observed that the introduction of mushy food occurred at an appropriate time, but liquids and solids were introduced early. The study detected the consumption of milk other than breast milk, water, teas, juices, fruits, vegetables, meat, and crackers. The authors also noted that the children's parents had a doctor, a speech therapist, and family members as their main sources of information for the introduction of complementary food, and a dietitian and the child's health book were also mentioned.

Gianni et al. ${ }^{10}$ developed a prospective study in Italy to investigate the timing and content of complementary feeding in a cohort of late preterm infants (born between 34 and 36 weeks), by contacting the mothers over the telephone in the first twelve months after delivery. Mothers started complementary feeding following pediatrician's advice in 


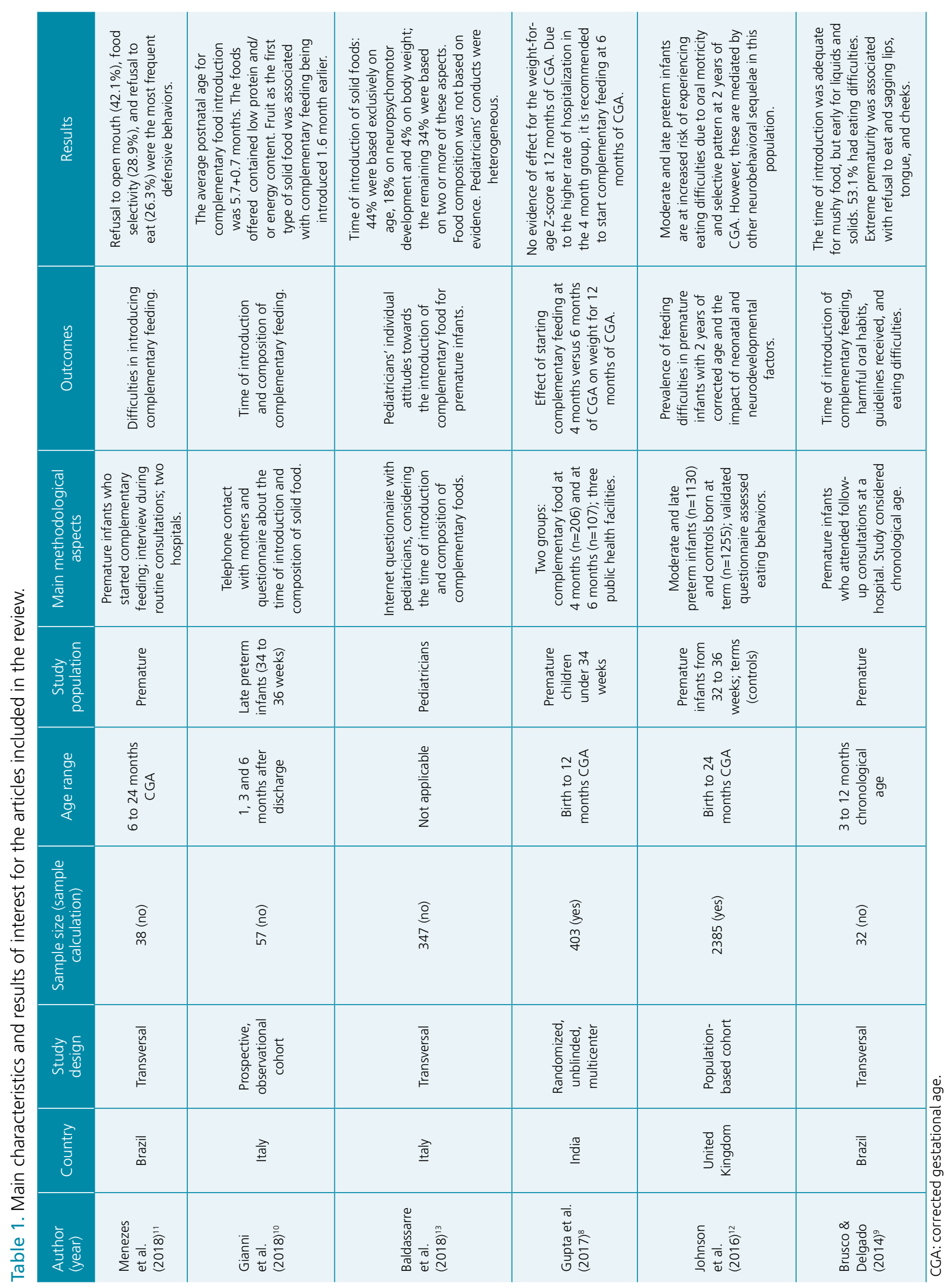


$88 \%$ of the cases but decided on their own in $12 \%$ of the cases. The average CGA for the introduction of complementary foods was $5.7 \pm 0.7$ months. The introduction of food started with low-calorie and/or protein foods in most cases. Fruit as the first type of complementary food was associated with complementary food being introduced 1.6 month earlier.

\section{Difficulties encountered and parents' perceptions of complementary feeding}

Three studies address the difficulties encountered in introducing complementary feeding. Both are transversal and use questionnaires that assess the perception of those responsible for the attitudes and behaviors of premature infants.

The two Brazilian studies involved preterm infants with a gestational age below 37 weeks: Menezes et al. ${ }^{11}$ evaluated children who started complementary feeding between six and 24 months of CGA; Brusco \& Delgado ${ }^{9}$ evaluated chronological children aged between three and 12 months. A United Kingdom study by Johnson et al. ${ }^{12}$, analyzed children born between 32 and 36 gestational weeks.

In general, the following aspects were evaluated: refusal to eat (low appetite, rejecting food, food selectivity); problems related to motor skills (biting, chewing, swallowing, choking, coughing); behavioral problems during mealtime (crying, tantrums, making a mess); gastrointestinal manifestations (nausea, vomiting, reflux) during or after meals. Complaints of nausea or vomiting were prevalent in both Brazilian studies and the three studies corroborate the association of prematurity with refusal to eat and behavioral problems.

Brusco \& Delgado 9 associate refusal to eat with extreme prematurity and extremely low birth weight due to admission to a neonatal intensive care unit and potential traumatic sequelae due to the use of tubes during treatment.

Menezes et al. ${ }^{11}$ associate refusal to eat with the use of formulas during a period that was supposed to include breastfeeding only, justifying difficulties in introducing new foods to multifactorial.

Brusco \& Delgado 9 and Menezes et al. ${ }^{11}$ converge in the hypothesis of low perception of parents about the manifestations of defensive behavior of children during complementary food introduction.

Johnson et al. ${ }^{12}$ concluded that children born between 32 and 36 gestational weeks have a greater chance of refusing food, and having motor and behavioral problems during the introduction of complementary feeding, when compared to those born at term. However, the authors attribute the findings to other neurobehavioral sequelae rather than to those assessed in the study.

\section{Conduct of health professionals towards complementary feeding}

From the perspective of health professionals, Baldassarre et al. ${ }^{13}$, in Italy, analyzed the conduct of pediatricians regarding complementary feeding of premature infants. This was a cross-sectional study carried out through a questionnaire sent to pediatricians in primary care through "Google Forms" platform. Of an estimated population of one thousand pediatricians, 347 participated. The study addressed the timing and composition of complementary feeding introduced to premature infants.

The authors found heterogeneity in relation to pediatricians' behavior when introducing complementary foods to premature children. Pediatricians were based on corrected gestational age, chronological age, weight or neurological development or, still, on the combination of two or more of these variables to indicate the time of food introduction. This means this topic is quite divergent. Regarding the initial composition of complementary feeding, there are also differences between the recommendations of these health professionals, with some of them not being in line with international recommendations.

\section{DISCUSSION}

Premature children had a higher nutritional requirement when compared to those born at term and, thus, the introduction of complementary feeding in a timely manner can supply this energy demand, preventing restricted postnatal growth, low weight, and neuropsychomotor deficit in the short term. It must be considered that preterm infants are a very heterogeneous population, since their gestational age at birth can vary between 23 and 36 weeks. Thus, the guidelines for the introduction of solid foods to children born at term cannot be used for premature infants, and the optimal time of introduction should consider motor development, higher nutritional needs, organ immaturity, increased intestinal permeability, and increased risk of hospitalization due to infections $s^{1,2}$.

As a brief history of the available recommendations, in 2001, the World Health Organization (WHO) ${ }^{14}$ started to recommend the introduction of complementary feeding at six months of age as a strategy to encourage breastfeeding. In 2008, the Committee of the European Society for Pediatric Gastroenterology, Hepatology and Nutrition (ESPGHAN $)^{15}$ reviewed current knowledge and practices and concluded that, in industrialized countries in Europe, the introduction of complementary feeding should not occur before 17 weeks (four months) and no later than 26 weeks (six months) of age. It should be noted that these two recommendations are aimed at children born at term. There is a recommendation for premature babies, published 
in 1994 in the United Kingdom ${ }^{16}$, saying the introduction of solid foods should start when a premature infant reaches a weight of $5 \mathrm{~kg}$, has lost the extrusion reflex, and is able to eat with a spoon. Unlike complementary feeding guidelines for term infants, this guideline does not include an age recommendation.

Based on limited evidence, a review study published in 2012 concludes that the corrected age of 3 months (13 weeks) may be appropriate for introducing solid foods for most preterm infants, considering good head control as an important milestone for safety ${ }^{1}$. However, some authors find acceptance difficulties related to motor skills with the introduction of complementary feeding at 3 months $s^{6,17}$.

The only randomized clinical trial found in the present review, carried out by Gupta et $\mathrm{al}^{8}$, recommends introducing complementary feeding for premature children up to six months of CGA, and weighing the risks and benefits of its introduction atfour months. The cross-sectional studies by Brusco \& Delgado ${ }^{9}$ and Gianni et al. ${ }^{10}$ reveal how inadequate complementary feeding of premature children is, both in terms of type of food and time of introduction, and also demonstrate how guidelines offered by health professionals influence parents' practices. The main limitations of these studies are: (a) Gupta et al. ${ }^{8}$ evaluated a vulnerable socioeconomic population in a developing country, (b) Brusco \& Delgado and Gianni et al. ${ }^{10}$ studied small- size groups, with no sampling; and (c) Brusco \& Delgado 9 analyzed children considering their chronological age.

The strategies followed in a nutritional intervention carried out with very-low-birth-weight preterm infants included: breast milk supplemented with a multi-component supplement, guidance on the introduction of semi-solid foods between four and six months of CGA, and monthly monitoring by a health team at home ${ }^{18}$. The intervention group was observed to have higher weight and head circumference at six months of CGA, indicating that the proposed nutritional intervention can potentially reduce growth restriction of premature infants in the period assessed ${ }^{18}$. Ensuring an ideal nutritional intake from birth and introducing solid foods in a timely manner and with an adequate composition of proteins, energy, and nutrients promote the adequate growth of premature children ${ }^{1,2}$.

Based on these considerations, the results found provide insight into dietary practices and highlight the need for multicenter randomized controlled trials specifically designed to assess when and how solid foods are introduced for premature infants and their benefits and risks.

Cross-sectional studies by Menezes et al. ${ }^{11}$, Brusco \& Delgado ${ }^{9}$, and Johnson et al. ${ }^{12}$ point out that difficulties related to complementary feeding are prevalent in premature children, especially behavioral issues and food refusal. Menezes et al. ${ }^{11}$ and Brusco \& Delgado ${ }^{9}$ raise the hypothesis that parents have little knowledge about the manifestations of their children's defensive behaviors during complementary feeding introduction. However, the following limitations should be considered: (a) Menezes et al. ${ }^{11}$ and Brusco \& Delgado9 used small samples and did not calculate the sample, which makes it difficult to infer data on other populations, and (b) the use of chronological age in the analysis performed by Brusco \& Delgado 9 may have generated bias in the association found between food refusal and extreme prematurity.

The period of complementary feeding is marked by exposure to new foods, tastes, and eating experiences. It coincides with the phase of children's rapid growth and development, in which they are susceptible to deficiencies and excesses of nutrients ${ }^{19}$. During the introduction of complementary feeding, brain and intestinal maturation is taking place, eating experiences help shape the connections involved in food sensations and the development of food preferences is already beginning ${ }^{20}$.

Premature children with lower gestational age or very low birth weight are more likely to have eating difficulties in the first year of life, manifested by oral-motor disorders and refusal to eat. Therefore, it is recommended that health professionals monitor the eating practices after hospital discharge to optimize the development of children's eating skills ${ }^{21,22}$. Prospective research and experimental design are necessary to verify the causal relationships between prematurity and eating difficulties, as well as to analyze the perception of those responsible for the children in this process.

According to the results of Baldassarre et al. ${ }^{13}$, a disparity in conduct from the perspective of health professionals can be attributed both to the lack of scientific evidence and to the lack of information dissemination, updating, training, and qualification of these professionals. These divergences regarding the use of parameters to guide the introduction of complementary food and its composition can have deleterious consequences. The child's neuromuscular development, with good head control for the safe intake of solid foods, should be assessed. There is no evidence to support the recommendation to introduce solid foods when children reach a bodyweight of $5 \mathrm{~kg}$, since children with postnatal growth restriction can benefit from solid foods before reaching this weight ${ }^{1,2,16,23}$. Thus, this is a vast field of research in the sense of providing evidence-based guidelines for health professionals to act in a standardized way in the care of premature children.

The present review highlights many gaps in the knowledge about complementary feeding of premature children. Little is known about what is considered ideal or what health professionals and caregivers are doing in practice. A situational diagnosis is required simultaneously with prospective multicenter 
experimental studies aimed at premature children. Such guidelines should include: (a) ideal time of introduction, such as difficulties and the appropriate nutritional composition of complementary food, (b) dissemination of this information to health professionals and caregivers, and (c) monitoring of these guidelines within the scope of health professionals and caregivers. In addition, we suggest developing further studies to investigate the immediate and long-term effects of healthy food introduction patterns and timing on the health of premature infants.

\section{AUTHORS" CONTRIBUTIONS}

BACF: Conceptualization; Data Curation; Formal Analysis; Investigation; Methodology; Project Administration; Writing - Original Draft; Writing - Review \& Editing. LML: Formal Analysis; Methodology; Writing - Original Draft; Writing - Review \& Editing. EEFP: Formal Analysis; Writing - Original Draft. TCS: Formal Analysis; Writing Original Draft. KOR: Formal Analysis; Writing - Original Draft. FOM: Writing - Original Draft. FGC: Writing Original Draft.

\section{REFERENCES}

1. Palmer DJ, Makrides M. Introducing solid foods to preterm infants in developed countries. Ann Nutr Metab. 2012;60(Suppl 2):31-8. https://doi.org/10.1159/000335336

2. Barachetti R, Villa E, Barbarini M. Weaning and complementary feeding in preterm infants: management, timing and health outcome. Pediatr Med Chir. 2017;39(4):181. https://doi. org/10.4081/pmc.2017.181

3. Barker DJ, Winter PD, Osmond C, Margetts B, Simmonds SJ. Weight in infancy and death from ischaemic heart disease. Lancet. 1989;2(8663):577-80. https://doi.org/10.1016/s01406736(89)90710-1

4. Wilson AC, Forsyth JS, Greene SA, Irvine L, Hau C, Howie PW. Relation of infant diet to childhood health: seven year follow up of cohort of children in Dundee infant feeding study. BMJ. 1998;316(7124):21-5. https://doi.org/10.1136/ bmj.316.7124.21

5. Fewtrell MS, Morley R, Abbott RA, Singhal A, Stephenson $T$, MacFadyen UM, et al. Catch-up growth in small-forgestational-age term infants: a randomized trial. Am J Clin Nutr. 2001;74(4):516-23. https://doi.org/10.1093/ajcn/74.4.516

6. Norris FJ, Larkin MS, Williams CM, Hampton SM, Morgan JB. Factors affecting the introduction of complementary foods in the preterm infant. Eur J Clin Nutr. 2002;56(5):448-54. https://doi.org/10.1038/sj.ejcn.1601336

7. Moher D, Liberati A, Tetzlaff J, Altman DG. Preferred reporting items for systematic reviews and meta-analyses: the PRISMA statement. PLoS Med. 2009;6(7):e1000097. https://doi. org/10.1371/journal.pmed.1000097

8. Gupta S, Agarwal R, Aggarwal KC, Chellani H, Duggal A, Arya $S$, et al. Complementary feeding at 4 versus 6 months of age for preterm infants born at less than 34 weeks of gestation: a randomised, open-label, multicentre trial. Lancet Glob Heal. 2017;5(5):e501-11. https://doi.org/10.1016/S2214109X(17)30074-8

9. Brusco TR, Delgado SE. Characterization of the feeding development of preterm infants between three and twelve months. Rev CEFAC. 2014;16(3):917-28. https://doi. org/10.1590/1982-021620145313

10. Giannì ML, Bezze E, Colombo L, Rossetti C, Pesenti N, Roggero $\mathrm{P}$, et al. Complementary Feeding Practices in a Cohort of Italian
Late Preterm Infants. Nutrients. 2018;10(12):1861. https:// doi.org/10.3390/nu10121861

11. Menezes LVP, Steinberg C, Nobrega AC. Complementary feeding in infants born prematurely. CoDAS. 2018;30(6):e20170157. https://doi.org/10.1590/2317-1782/20182017157

12. Johnson S, Matthews R, Draper ES, Field DJ, Manktelow BN, Marlow N, et al. Eating difficulties in children born late and moderately preterm at $2 \mathrm{y}$ of age: a prospective populationbased cohort study. Am J Clin Nutr. 2016;103(2):406-14 https://doi.org/10.3945/ajcn.115.121061

13. Baldassarre ME, Di Mauro A, Pedico A, Rizzo V, Capozza M, Meneghin $F$, et al. Weaning time in preterm infants: an audit of italian primary care paediatricians. Nutrients. 2018;10(5):616. https://doi.org/10.3390/nu10050616

14. World Health Organization: 54th World Health Assembly global strategy for infant and young child feeding: the optimal duration of exclusive breastfeeding. Geneva: World Health Organization; 2001. [cited on Jul. 26, 2020]. Available from: https://apps.who.int/iris/handle/10665/78801

15. Agostoni C, Decsi T, Fewtrell M, Goulet O, Kolacek S, Koletzko $B$, et al. Complementary feeding: a commentary by the ESPGHAN Committee on Nutrition. J Pediatr Gastroenterol Nutr. 2008;46(1):99-110. https://doi.org/10.1097/01. mpg.0000304464.60788.bd

16. Weaning and the weaning diet. Report of the Working Group on the Weaning Diet of the Committee on Medical Aspects of Food Policy. Rep Health Soc Subj (Lond). 1994;45:1-113. PMID: 7701106

17. Jonsson M, van Doorn J, van den Berg J. Parents' perceptions of eating skills of pre-term vs full-term infants from birth to 3 years. Int J Speech Lang Pathol. 2013;15(6): 604-12. https:// doi.org/10.3109/17549507.2013.808699

18. Japakasetr S, Sirikulchayanonta C, Suthutvoravut U, Chindavijak B, Kagawa M, Nokdee S. Implementation of a nutrition program reduced post-discharge growth restriction in thai very low birth weight preterm infants. Nutrients. 2016;8(12):820 https://doi.org/10.3390/nu8120820

19. Fewtrell M, Bronsky J, Campoy C, Domellöf M, Embleton $N$, Fidler Mis N, et al. Complementary Feeding: A Position Paper by the European Society for Paediatric Gastroenterology, 
Hepatology, and Nutrition (ESPGHAN) Committee on Nutrition. J Pediatr Gastroenterol Nutr. 2017;64(1):119-32. https://doi. org/10.1097/MPG.0000000000001454

20. Nicklaus S. Complementary Feeding Strategies to Facilitate Acceptance of Fruits and Vegetables: A Narrative Review of the Literature. Int J Environ Res Public Health. 2016;13(11):1160. https://doi.org/10.3390/ ijerph13111160

21. Pagliaro $C L$, Bühler KEB, Ibidi SM, Limongi SC. Dietary transition difficulties in preterm infants: critical literature review. J Pediatr. 2016;92(1):7-14. https://doi.org/10.1016/j. jped.2015.05.004

22. DeMauro SB, Patel PR, Medoff-Cooper B, Posencheg M, Abbasi S. Postdischarge feeding patterns in early- and late-preterm infants. Clin Pediatr (Phila). 2011;50(10):957-62. https://doi. org/10.1177/0009922811409028

23. Marriott LD, Foote KD, Bishop JA, Kimber AC, Morgan JB. Weaning preterm infants: a randomised controlled trial. Arch Dis Child Fetal Neonatal Ed. 2003;88(4):F302-7. https://doi. org/10.1136/fn.88.4.f302 